\title{
Microbiota de jamones de cerdo cocidos asociada al deterioro por abombamiento del empaque
}

\author{
Microbial of cooked pork hams associated of blown pack \\ spoilage
}

\author{
Juliana Ossa, 1*B.Sc, Adriana Coral, 2M.Sc, María Vanegas L, ${ }^{1}$ M.Sc.
}

\begin{abstract}
'Universidad de los Andes, Facultad de Ciencias Biológicas, Grupo de Investigación del Laboratorio de Ecología Microbiana y de Alimentos, LEMA. ²Laboratorio Carulla Vivero S.A. Zona Industrial, Bogotá, Colombia.*Correspondencia: ja.ossa907@uniandes.edu.co
\end{abstract}

Recibido: Noviembre 25 de 2009: Aceptado: Junio 23 de 2010.

\section{RESUMEN}

Objetivo. Caracterizar la diversidad microbiana y calidad microbiológica e higiénico sanitaria de diferentes marcas de jamones de cerdo cocidos abombados y no abombados comprados en varios supermercados de Bogotá D.C. Materiales y métodos. Se analizaron 10 marcas diferentes de jamones de cerdo cocidos comprados en tres supermercados, refrigerados bajos las mismas condiciones del consumidor, durante 45 días. Se realizó los recuentos en placa de microorganismos de interés en la industria de alimentos y de inocuidad en las muestras con o sin distensión del empaque e identificación por pruebas bioquímicas y PCR para determinar la diversidad de la microbiota. Se aislaron cepas productoras de biopelículas provenientes de la superficie de una planta de alimentos de una de las marcas de los jamones investigadas. Resultados. Se identificaron un total de 139 cepas aisladas del producto terminado, de las cuales un 99\% (137 cepas) pertenecen al grupo de Bacterias Acido Lácticas (BAL), el 1\% restante son levaduras. De las 31 cepas aisladas de las superficies en la zona de tajado, el 97\% ( 30 cepas) presentaron formación de biopelículas. Se determinó ausencia de patógenos tanto en el producto terminado como en las muestras de las superficies. Conclusiones. El deterioro causado por abombamiento del empaque fue asociado a la presencia de $\mathrm{BAL}$, debido a que fueron encontradas en la zona de tajado y en el producto terminado, de este último únicamente se aislaron $\mathrm{BAL}$, en mayor proporción cepas correspondientes al género de Lactobacillus sp.

Palabras clave: Bacterias acido lácticas, jamón cocido, biopelículas. 


\section{ABSTRACT}

Objetive. Characterization of microbial diversity and microbiological quality and hygienic sanitary evaluation of different brands of cooked pork ham stunned naturally and not stunned set in several supermarkets of Bogotá D.C. Materials and methods. Were analyzed 10 brands of cooked pork ham during 45 days, refreshed in fridge low the same conditions of the consumer, from three different supermarkets. Recounts in plate of important microorganism in the industry of food and of innocuousness were done to sample with or without blown pack and the isolated strains were identified by biochemical tests and molecular biology (PCR) to determine microbial diversity present of the samples and also food-borne-pathogens. Additionally biofilm formation by strains isolated from surfaces in a food industry was tested. Results. 139 strains were isolated from finished product, which 99\% (137 strains) belong are classified into lactic acid bacteria group (LAB), the remaining $1 \%$ corresponding to yeasts. From 31 strains isolated from surfaces in the sliced zone, 97\% (30 strains) presented biofilm formation. Food-borne pathogens were not isolated from finished product or environmental samples. Conclusions. The spoilage caused for blown pack was associated with presence of $L A B$, due the fact they were isolated from collected samples in the sliced zone and finished product, of this one only LAB were isolated specially Lactobacillus sp.

Key words: Acid lactic bacteria, pack spoilage, cooked ham, biofilms.

\section{NTRODUCCIÓN}

En Colombia, existen aproximadamente 17 empresas nacionales registradas dedicadas a la producción de productos cárnicos procesados, entre ellos, el jamón cocido representó ventas por 28 millones de dólares para el año 2002 (1).

El jamón es descrito como un alimento o producto cárnico procesado listo para el consumo, manipulado, elaborado, cocido (tratamiento térmico con temperatura mínima de $72^{\circ} \mathrm{C}$, optima $80^{\circ} \mathrm{C}$ ), embutido, moldeado o prensado, elaborado con musculo, grasa o vísceras provenientes de animales de abasto, entero o troceado, con la adición de sustancias de uso permitido y listo para el consumo (2). Está clasificado dentro de los alimentos embutidos escaldados bajos en acidez, que comprenden la mayor variedad de subproductos cárnicos (3).

Para los productos cárnicos procesados cocidos; existen unos parámetros microbiológicos con ciertos rangos de valores máximos permisibles para identificar su nivel de buena calidad, como: coliformes ( 100 UFC/g), Staphylococcus aureus coagulasa positiva $(<100 \mathrm{UFC/g})$, Listeria monocytogenes (/25), Salmonella (/25),
Esporas Clostridium sulfito reductor $(<10$ $\mathrm{UFC} / \mathrm{g}$ ), Escherichia coli (<10 UFC/g) (2).

Las alteraciones generadas por ciertos microorganismos se enfatizan principalmente en las descomposiciones y la producción de gases como dióxido de carbono que alteran el empaque y al producto como tal, debido a la actividad glicolítica donde se genera abundante cantidad de ácidos como sulfhidríco, ácido láctico, variando el pH, el olor, estas alteraciones son consecuencias de una refrigeración insuficiente. Es así, como después que el pH disminuye, la flora Gram positiva acompañante prevalece, imponiéndose microorganismos del género Lactobacillus spp. y en ocasiones algunos Gram negativos como las enterobacterias (4). En los alimentos cárnicos almacenados en ausencia de oxígeno, la microbiota alterante está dominada por las bacterias lácticas. Sin embrago, si el pH del tejido muscular es alto o si hay cantidades residuales de oxígeno, otros microorganismos, como Brochothrix thermosphacta y Staphylococcus putrefaciens contribuyen sustancialmente a la alteración del producto (4).

Referente a los microorganismos encontrados 
en los equipos, los ambientes, los manipuladores y las instalaciones los indicadores podrían ser microorganismos mesófilos, hongos y levaduras; por esto, es la importancia de evaluar las bacterias contaminantes del ambiente que se encuentran adheridas formando las microcolonias o las biopelículas en las superficies.

Las biopelículas son comunidades complejas de microorganismos presentes en los ambientes naturales formadas por las asociaciones de una o múltiples especies con una determinada organización, que pueden colonizar superficies; las biopelículas no solo son las bacterias, sino también, el material que se produce sobre una matriz, que se pude adherir en pocos minutos dando paso a la formación de una biopelícula en un tiempo de horas y días (5). Están compuestas principalmente por polisacáridos, proteínas y algunas veces pueden contener lípidos, ácidos nucleícos y otros biopolímeros. El término biopelículas o mejor conocido como "biofilm" se refiere a la actividad biológica sobre una matriz celular y a la asociación de sustancias extracelulares en una superficie solida (5).

En la industria de alimentos, la presencia de biofilms ocasiona problemas como el incremento de la transferencia de calor o el aumento de la resistencia a agentes antimicrobianos en las superficies $(5,6)$. Adicionalmente, pueden ocasionar deterioro, contaminación cruzada, contaminación ambiental y principalmente contaminación post-proceso por la liberación continua de bacterias que afectan la producción y calidad de los productos, en ocasiones son bacterias patógenas para humanos de importancia en salud pública u en otras por bacterias ambientales que tienen la misma capacidad de adherencia ocasionando problemas en el proceso como tal $(6,7)$.

En la industria cárnica nacional, es relativamente frecuente la aparición del abombamiento en los jamones de cerdo cocidos debido a la dificultad de mantener en las perfectas condiciones la cadena de frio, y esta problemática se ve reflejada en pérdidas económicas para la industria de alimentos. "Blown pack spoilage" o producción de gas entre las láminas de la carne, se reportó por primera vez en países como U.S.A. en el año de 1989, Reino Unido (1989), Nueva Zelanda (1996) e Irlanda (2000) muestra pérdidas de aproximadamente 1.125 millones de pesos (€375.000) (8), cifras que evidencian la importancia de los perjuicios económicos a las empresas de alimentos en relación a este tipo de deterioro. Varios autores han reportado algunos microorganismos como las bacterias acido lácticas, enterobacterias psicrotolerantes como Hafnia, Enterobacter, Serratia, Rahnella y Ewingella, en recuentos de $10^{6}$ UFC, las cuales han sido relacionadas a las muestras de jamones abombados empacados al vacío a $4{ }^{\circ} \mathrm{C}$; adicionalmente, Clostridium siendo muy frecuentes las especies de C. gasigenes y $C$. estertheticum, como causantes del blown pack en países como Nueva Zelanda (9-11).

Se desconoce la ecología microbiana asociada a este fenómeno, específicamente el agente causal del abombamiento en los jamones de cerdo cocidos empacados al vacío de producción nacional. Todo esto lleva a considerar la importancia cada vez mayor de caracterizar los microorganismos causantes del deterioro empleando técnicas de microbiología tradicional que aportan información importante para la industria cárnica permitiendo comprender la diversidad microbiana parcialmente identificada en estudios anteriores. Esta investigación, es la primera en Colombia que aborda esta problemática de la industria de alimentos proporcionando información importante de control y puntos de partida para el óptimo manejo de la calidad de los productos terminados al consumidor.

El objetivo de esta investigación fue caracterizar la diversidad microbiana y calidad higiénica sanitaria de diferentes marcas de jamones de cerdo cocidos abombados naturalmente y no abombados procedentes de diferentes supermercados de Bogotá. 


\section{MATERI ALES Y MÉTODOS}

Muestreo. Se recolectaron 10 marcas diferentes de jamones de cerdo cocidos comprados en tres cadenas de supermercados de Bogotá, se mantuvieron en la nevera a temperatura que oscilaba entre 6- $9 \pm 0.1^{\circ} \mathrm{C}$, bajo las mismas condiciones de refrigeración del consumidor, durante 45 días. Los jamones que presentaron abombamiento del empaque fueron procesados en un rango de 10-15 días después de la aparición de las primeras burbujas de gas entre las láminas de carne. Los jamones que no presentaron abombamiento se procesaron entre 10-15 días después de la fecha de caducidad. El criterio de escogencia, fueron jamones de cerdo, que mantuvieran un rango parecido en tiempo de la fecha de caducidad, ninguna de las muestras sobrepaso la fecha de vencimiento. Posteriormente, se realizaron recuentos bacterianos en placa e identificación por pruebas bioquímicas y pruebas moleculares como PCR.

Recuento en placa de microorganismos. Se agregaron $25 \mathrm{~g}$ de jamón a $225 \mathrm{ml}$ de agua peptonada al $0.1 \% \mathrm{p} / \mathrm{v}$, de esta forma se obtuvo la dilución $10^{-1}$. Se realizaron diluciones seriadas y se sembró en cada medio de cultivo diferencial. Después de dejar incubando cada medio de cultivo a las condiciones optimas de cada microorganismo de interés, se realizaron recuentos de las colonias características. Cada protocolo se realizó por duplicado.

I dentificación de microorganismos por microbiología tradicional. Se tomaron muestras del producto final que presentaron abombamiento y las muestras que no presentaron distensión del empaque, en donde se caracterizó la microbiota presente según los protocolos del INVIMA con modificaciones (12); para el aislamiento y el recuento de los microorganismos; se clasificaron y agruparon las colonias por diferencias macroscópicas, microscópicas, se confirmaron por pruebas bioquímicas especificas de cada especie, y métodos rápidos como ID System/BD (BBL ${ }^{\circledR}$ Crystal $^{\mathrm{TM}}$, NJ , USA) y API (Biomerieux).
Recuento de mesófilos aerobios. En cajas de petri con medio PCA Plate Count Agar, (Sharlau, Barcelona, España), incubadas a $30 \pm 0.2^{\circ} \mathrm{C}$ por $24 \mathrm{~h}$ (12).

Recuento de psicrófilos. En cajas de petri con medio PCA Plate Count Agar (Sharlau, España), incubados a $4 \pm 0.2^{\circ} \mathrm{C}$ durante 7 días $(12,13)$.

Recuento de bacterias ácido lácticas (BAL). Las bacterias con morfología de bacilos Gram positivos se cultivaron en agar y caldo MRS en condiciones de aerobiosis (Man Rogosa sharpe, SharlauEspaña)( $30 \pm 0.2^{\circ} \mathrm{C}$ por $\left.48 \mathrm{~h}\right)$, se realizaron pruebas de catalasa, para clasificarlas entre los géneros de las BAL. Para la confirmación de Lactobacillus spp., se realizó PCR con primers de $256 \mathrm{pb}$, fragmento que corresponde a la región rADN 16-23S, LbLMA1-Rev: 5' - CTC AAA ACT AAA CAA AGT TTC-3', R16-1: 5' - CTT GTA CAC ACC GCC CGT CA-3' (14). Para la identificación de otros géneros de BAL, como cocos Gram positivos, se realizaron pruebas bioquímicas como catalasa, oxidasa y fermentación de azucares (15).

Recuento de bacterias sulfito reductoras. Se realizó en doble capa de agar SPS (Perfringens Selective Agar, Merck), incubados a $35 \pm 0.2^{\circ} \mathrm{C}$ por $72 \mathrm{~h}$ (12).

NMP de coliformes fecales y coliformes totales. Para el recuento de coliformes fecales y coliformes totales se utilizó el caldo Fluorocult LMX (Merck, U.S.A), incubados a $35 \pm 0.2^{\circ} \mathrm{C}$ por $24 \mathrm{~h}$ (16).

Recuento de Pseudomonas aeruginosa. Se realizó en cajas de petri que contenían el medio de cultivo cetrimide-Difco, con glicerol, incubadas a $35 \pm 0.2^{\circ} \mathrm{C}$ por $24 \mathrm{~h}$ (12).

Recuento de levaduras. En las cajas de petri con agar PDA acidificado (Potato Dextrose Agar, Oxoid-Inglaterra), incubadas a $25 \pm 0.2^{\circ} \mathrm{C}$ por 5 días (12).

Recuento de Staphylococcus aureus. En las cajas de petri con agar Baird Parker (Sharlau, Barcelona, España), incubados a $35 \pm 0.2^{\circ} \mathrm{C}$ por $24 \mathrm{~h}$ (12). 
Ausencia o presencia de Salmonella sp. Se realizó pre-enriquecimiento con $25 \mathrm{~g}$ de jamón en $225 \mathrm{~mL}$ de agua peptonada al 0.1\% $\mathrm{p} / \mathrm{v}$ durante $24 \mathrm{~h}$, enriquecimiento en caldo Rapaport (Sharlau, Barcelona, España) y caldo Müller kauffmann caldo base Tetrationato durante $24 \mathrm{~h}$ a $42 \pm 0.2^{\circ} \mathrm{C}$, luego se realizó siembra por aislamiento en agar Hecktoen (Oxoid, UK, England) y se incubó a $35 \pm 0.2^{\circ} \mathrm{C}$ por $24 \mathrm{~h}$ ( 12 ).

\begin{abstract}
Ausencia o presencia de Listeria monocytogenes. Se realizó enriquecimiento en caldo basal de UVM (Oxoid, USA); luego por aislamiento se sembró en agar Palcam- (Oxoid, USA); se incubó a $35 \pm 0.2^{\circ} \mathrm{C}$ por $24 \mathrm{~h}$ (12). Las colonias características de Listeria monocytogenes por morfología macroscópica fueron confirmadas por PCR con primers específicos, Gen hlyO, LM1: 5' -CGG-AGG-TTCCGC-AAA-AGA-TG-3', LM2: 5' -CCT-CCA-GAGTGA-TCG-ATG-TT-3'.
\end{abstract}

Toma de las muestras de las superficies de la zona de tajado de la planta. Se tomaron las muestras con hisopos de un área aproximada de $100 \mathrm{~cm}^{2}$ de las superficies de una planta de alimentos (17), que procesa cuatro de las marcas evaluadas en el estudio. Se incluyeron varias zonas: las cuchillas de metal, máquina de tajado, la mesa de producción y la banda transportadora de plástico. Las cuatro zonas están comprometidas en el mismo espacio.

Evaluación de las biopelículas. Para la determinación de biopelículas se llevó a cabo el procedimiento reportado por O'Toole (18).

Conservación de las cepas. A partir de los recuentos se aislaron las diferentes colonias y se mantuvieron en cultivos puros para posterior identificación. Las cepas puras aisladas de las muestras fueron conservadas a $-20^{\circ} \mathrm{C}$ y $-80^{\circ} \mathrm{C}$ en caldo BHI Brain Heart Infusion, (Oxoid, UK, England) con $30 \% \mathrm{v} / \mathrm{v}$ de glicerol.

Cepas de referencia. Las cepas utilizadas como control positivo en el estudio fueron, Staphylococcus aureus ATCC 2593, Lactobacillus plantarum WS4174, E. coli ATCC
25922, P. aeruginosa ATCC 10145, Listeria monocytogenes ATCC 19115, Salmonella typhi ATCC 6539.

\section{RESULTADOS}

De las 10 muestras de marcas de jamones de cerdo cocidos, 4 presentaron abombamiento y las 6 restantes no presentaron distensión del empaque. Aquellas que presentaron abombamiento se procesaron aproximadamente a los 10 días del inicio de la aparición de las burbujas de gas, y las muestras que no presentaron abombamiento se dejaron en refrigeración $\left(6-9 \pm 0.2^{\circ} \mathrm{C}\right)$ durante 45 días y se procesaron entre 10 a 15 días después de cumplir la fecha de caducidad. En la figura 1, se puede observar que los mayores recuentos pertenecen a jamones abombados en donde se aprecian los valores promedios de recuentos expresados en UFC/g.

El máximo recuento bacteriano en todas las muestras correspondió a las BAL, seguido por los psicrófilos en algunas muestras, siendo los mayores recuentos de las BAL en las muestras que presentaron abombamiento respecto a las que no presentaron. En las marcas que presentaron distensión del empaque; se observan recuentos de $\mathrm{BAL} 10^{8}-10^{9} \mathrm{UFC} / \mathrm{g}$, sin embargo, las BAL arrojaron menores recuentos (106 $\mathrm{UFC} / \mathrm{g}$ ) en las marcas que no presentan abombamiento, disminuyendo aproximadamente 3 valores exponenciales respecto a las muestras abombadas. En cuanto, al recuento de psicrófilos el mayor fue de $10^{8} \mathrm{UFC} / \mathrm{g}$ en una marca de los jamones abombados y $10^{6} \mathrm{UFC} / \mathrm{g}$ en los jamones que no presentaron blown pack y el menor recuento fue $10^{4} \mathrm{UFC} / \mathrm{g}$ en todas las muestras. Los mesófilos mostraron recuentos de $10^{8} \mathrm{UFC} / \mathrm{g}$ en una sola marca de jamón abombado, las demás incluyendo marcas de jamón abombado y no abombado se mantenían en un rango de $10^{6} \mathrm{UFC} / \mathrm{g}$ (Figura 1). De dos muestras no se obtuvo recuento bacteriano debido a que no estaban dentro del rango de diluciones manejado en la metodología utilizada.

De igual forma, de los tres medios utilizados para caracterizar la microbiota del producto terminado (MRS, PCA, PDA acidificado), únicamente se recuperaron bacterias acido 

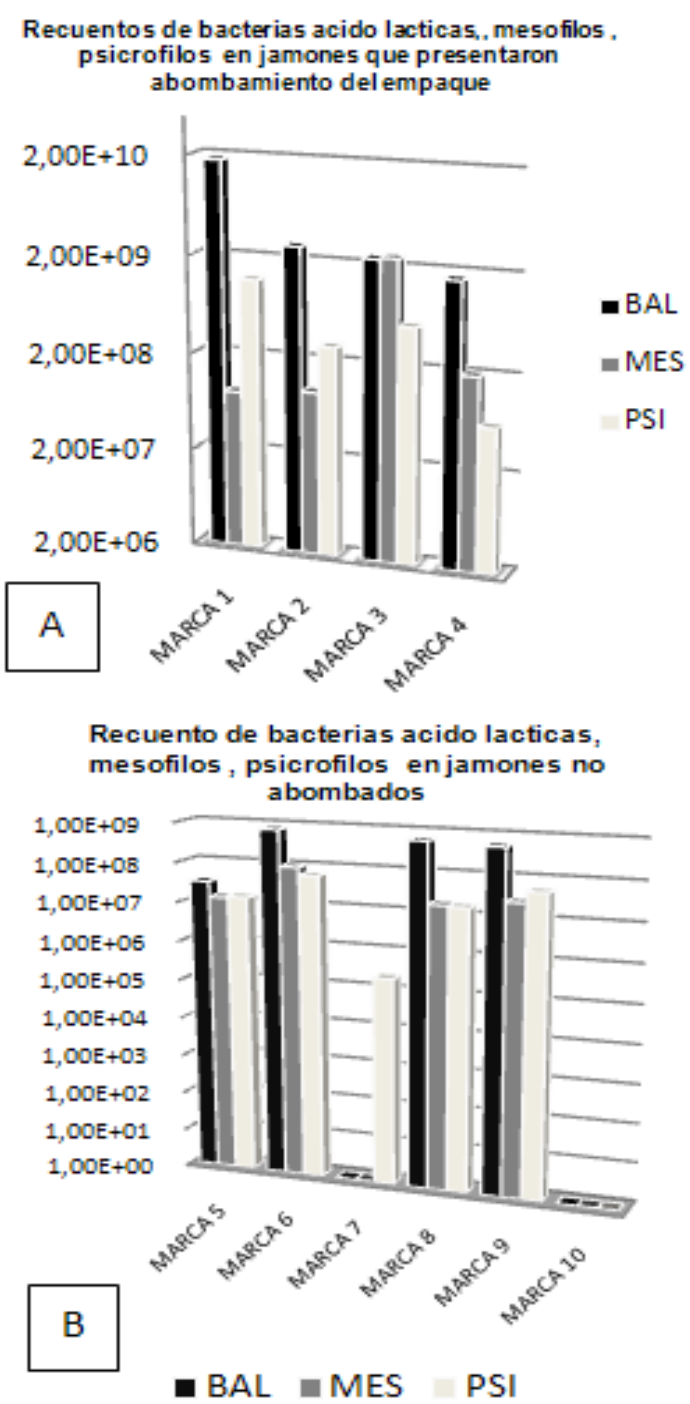

Figura 1. Recuentos microbiológicos de las diez marcas A. 4 marcas nacionales que corresponden a jamones abombados, B. 6 marcas nacionales que corresponden a muestras de jamones de cerdo cocidos que no presentaron abombamiento.

lácticas y 2 levaduras, en donde se evidenció la capacidad de crecimiento de las BAL en medios de cultivo diferentes al MRS, como es PCA.

Para la caracterización de las cepas aisladas a partir de los diferentes medios de cultivo utilizados, se identificaron un total de 139 cepas aisladas de producto terminado de muestras abombadas y no abombadas, de las cuales un 99\% pertenecian al grupo de bacterias ácido lácticas (BAL) aisladas de MRS y PCA, 2 (1\%) cepas fueron levaduras aisladas de PDA. De las
139 cepas aisladas de las muestras, 37 pertenecen a géneros de BAL como Leuconostoc, Lactococcus, Oenococcus, y 100 al género Lactobacillus spp.

En cuanto a la evaluación de patógenos en jamones abombados y no abombados, Salmonella spp., L. monocytogenes, bacterias sulfito reductoras, Pseudomonas aeruginosa, Staphylococcus aureus, coliformes totales y fecales, muestran el mismo comportamiento; fueron negativos y tuvieron recuentos de $<100$ UFC/g S. aureus coagulasa positiva, sulfito reductores, P. aeruginosa. Para E.coli y coliformes totales presentaron resultados <3NMP; ausencia de Salmonella spp. /25g, ausencia L. monocytogenes $/ 25 \mathrm{~g}$. Por lo anterior, únicamente se identificaron BAL aisladas de MRS y PCA, mesófilos aerobios y psicrófilos de PCA que correspondían a géneros de BAL.

Los resultados obtenidos por pruebas bioquímicas de catalasa, oxidasa, microscopia y PCR con primers específicos (LbLMA1-R16-1), confirmaron la presencia de Lactobacillus spp. en las muestras de jamones abombados y no abombados. Los demás géneros de BAL fueron identificados por pruebas bioquímicas, dentro de los cuales están cocos Gram positivos catalasa negativa como Leuconostoc, Lactococcus, Oenococcus, presentes en muestras de jamones no abombados en mayor proporción. Además, de determinó la ausencia de L. monocytogenes usando PCR con primers específicos (LM1-LM2).

Tabla 1. Cepas aisladas de la superficie de la zona de tajado con propiedad de formación de biopelículas

\begin{tabular}{lc}
\hline \multicolumn{1}{c}{ Microorganismos } & No. Cepas \\
\hline Lactobacillus spp. & 2 \\
Pseudomonas fluorescens & 4 \\
Micrococcus luteus & 7 \\
Micrococcus varians & 9 \\
Micrococcus sedentarius & 2 \\
Enterobacter gergoviae & 2 \\
Edwarsiella ictaluri & 2 \\
Pseudomonas oryzihabitans & 1 \\
Burkholderia cepacia & 1 \\
Bacillus alvei & 1 \\
\hline Total & 31 \\
\hline
\end{tabular}


De las 31 cepas aisladas de las superficies en la zona de tajado e identificadas por pruebas bioquímicas y métodos rápidos, se diferenciaron 7 géneros, de los cuales el 97\% presentó formación de biopelículas, incluyendo cepas de Lactobacillus spp., solamente una cepa de M. luteus no formó biopelícula (Tabla 1).

\section{DISCUSIÓN}

El jamón por su alto contenido nutricional, permite el desarrollo de microorganismos deteriorantes. Según los resultados obtenidos en este estudio, se evidenció distensión del empaque entre 20 y 30 días antes de la fecha de caducidad o tiempo de vida útil bajo refrigeración. En donde se alcanzaron recuentos bacterianos en unidades logarítmicas entre $10^{8}-10^{9} \mathrm{UFC} / \mathrm{g}$ en producto terminado abombado. Lo anterior coincide con la densidad celular máxima alcanzada en condiciones de anaerobiosis en productos empacados al vacio reportados por otros autores $10^{7}-10^{8} \mathrm{UFC} / \mathrm{cm}^{2}(4,9,11)$. Los recuentos de BAL y psicrófilos fueron similares en algunas marcas que presentaron abombamiento, debido a que se puede estar recuperando los mismos géneros de BAL en los diferentes medios, MRS y PCA para mesófilos y psicrófilos, debido a que estas pueden desarrollarse en los diferentes medios de cultivo mencionados anteriormente, aunque no sean medios selectivos para las BAL.

Tanto de jamón abombado y no abombado se aislaron únicamente cepas de BAL, demostrando que la diferencia entre jamones que no presentaron abombamiento con los que presentaron blown pack se atribuía al incremento en dos o tres unidades exponenciales a las muestras deterioradas. Adicionalmente, no se evidenció presencia de microorganismos patógenos que pueden ser transmitidos por alimentos.

En cuanto a la diversidad microbiana asociada al deterioro, en nuestro estudio se encontraron bacterias acido lácticas tales como Leuconostoc, Lactococcus, Oenococcus, y Lacotabacillus, reportadas anteriormente como deteriorantes. Microorganismos como Carnobacterium,
Pediococcus, Enterococcus y Brochothrix thermosphacta, no fueron encontrados en las muestras trabajadas $(4,19,20)$. En relación a esto, las condiciones del empaque favorecen el desarrollo de las BAL como los Lactobacillus spp., aislados en mayor proporción del producto terminado que se han introducido en alguna de las etapas del proceso.

Las BAL están en producto terminado debido a diferentes causas, una de ellas es la recontaminación después del termoproceso por la inadecuada manipulación, permite la supervivencia de los microorganismos deteriorantes presentes en superficies que resisten la efectividad de los programas de limpieza y desinfección, remociones mecánicas y químicas causando la formación de biopelículas.

Además, el mantenimiento de la cadena de frio que es un punto critico de control que no debe ser descuidado por la industria cárnica, puesto que es la principal causa de disminución de la vida de anaquel, favorece el crecimiento de bacterias psicotróficas que siendo mesófilas pueden desarrollarse aceleradamente a temperaturas entre $0-4^{\circ} \mathrm{C}$ o a temperaturas mayores entre $6-8^{\circ} \mathrm{C}$ cuando se pierde continuidad en la refigeración. Las BAL logran persistir en el producto cuando se han incorporado en las etapas de producción posteriores al tratamiento térmico $(4,21)$.

La presencia de la gran diversidad de la microbiota productora de biopelículas en la zona de tajado que coinciden con lo reportado en la literatura como algunos géneros de Pseudomonas, Enterobacter, Bacillus, Micrococcus y cepas de Lactobacillus spp. $(5-7,22)$, estos últimos, contaminando los bloques de jamón de las marcas evaluadas que son procesados por la maquina, aparecen en el producto final ocasionando blown pack.

Las razones por las cuales las demás cepas aisladas de la zona de tajado pueden desaparecer en el producto terminado son debido a las condiciones internas del empaque al vacío que se modifican cuando se da el abombamiento y alteran la microbiota 
acompañante. Las concentraciones de $\mathrm{CO}_{2}$ y al pH ácido inhiben la proliferación de microbiota diferente a las BAL, en donde estas últimas pueden adaptarse a estas condiciones atmosféricas dentro del empaque (20).

Finalmente, el deterioro conocido como "blown pack", ha sido ocasionado por Clostridium sp, enterobacterias, bacterias acido lácticas, reportadas en estudios anteriores; en esta investigación no se aislaron bacterias sulfito reductoras ni bacterias de la familia Enterobacteriacceae lo que indica que el deterioro esta siendo ocasionado por otro grupo de microorganismos anaerobios que sobreviven a las temperaturas de refrigeración, bacterias pertenecientes al género de las $B A L$, específicamente cepas de Lactobacillus spp.
En conclusión, en las etapas posteriores al procesamiento térmico final, el jamón está expuesto a contaminación cruzada desde superficies en las cuales bacterias deteriorantes formadoras de biopelículas como Lactobacillus spp. entran en contacto con el producto terminado, lo anterior sumado a problemas con el mantenimiento de la cadena de frio durante la producción y comercialización ocasionan el deterioro por blown pack.

\section{Agradecimientos}

A la Universidad de los Andes, Facultad de Ciencias Biológicas, Laboratorio de Ecología Microbiana y de Alimentos, (LEMA).

\section{REFERENCI AS}

1. Oficina Económica y Comercial de la Embajada de España en Bogotá. El sector de los procesados cárnicos en Colombia. Notas sectoriales. [Serial online] 2005 Feb [Citado 7 Mar 2010]; 1(1): URL Disponible en: http://www.oficinascomerciales.es/ icex/cma/contentTypes/common/records/ viewDocument/0,,,00. bin?doc $=456268$.

2. Instituto Colombiano de Normas Técnicas y Certificación (ICONTEC) Norma Técnica Colombiana. NTC 1325. Industrias alimentarias. Productos cárnicos procesados no enlatados. Quinta actualización, Bogota D.C: ICONTEC; 2008.

3. Guzmán CD. Caracterización del canal de comercialización de productos cárnicos madurados en Colombia [tesis de pregrado]. Colombia: Nacional Univ.; 2004.

4. Doyle PM, Beuchat RL, Montville JT. Microbiología de los alimentos: fundamentos y fronteras. España: Acribia editores; 2001.

5. Chmielewski RAN, FrankJ F. Biofilm Formation and Control in Food Processing Facilities. CRFSFS 2003; 2(1):22-32.

6. Jessen B, Lammert L. Biofilm and desinfection in meat processing plants. Int Biodet 2003; 51(4):265-269.
7. Sharma M, Anand SK. Characterization of constitutive microflora of biofilms in dairy processing lines. Food Microbiol 2002; 19:627-636.

8. Bolton JD, Moschonas G, Sheridan JJ. Control of Blown Pack Spoilage in Vacuum Packaged Meat, reporte número 101. Ashtown Food Research Centre, Research $\&$ training for the food industry. [serial on line] 2009. [citado 25 de Abril de 2010]; 1(1). URL Disponible en:http:// www. teagasc.ie/research/reports/ foodprocessing/5417/eopr-5417. pdf

9. Broda DM, Bell RG, Boerema JA, Musgrave DR. The abattoir source of culturable psychrophilic Clostridium spp. causing 'blown pack' spoilage of vacuum packed chilled venison. J Appl Microbiol 2002; 93: 817-824.

10. Boerema JA, Broda DM, Penney N, Brightwell G. Influence of Peroxyacetic Acid-Based Carcass Rinse on the Onset of "Blown Pack" Spoilage in Artificially Inoculated Vacuum-Packed Chilled Beef. J Food Prot 2007; 70(6): 1434- 1439. 
11. Brightwell G, Clemens R, Urlich S, Boerema J. Possible involvement of psychrotolerant Enterobacteriacceae in blown pack spoilage of vacuum packaged raw meats. IntJ Food Microbiol 2007; 119: 334-339.

12. Instituto Nacional de Vigilancia de Medicamentos y Alimentos I NVIMA. Manual de técnicas de análisis para control de calidad microbiológico de alimentos para consumo humano. Bogota: INVI MA 1998.

13. International Organization for Standarization (ISO). Norma ISO 17410. Microbiology of food and animal feeding stuffs Horizontal method for the enumeration of psychrotrophic microorganisms. ISO 2001.

14. Dubernet S, Desmasures N, Gueguen MA. PCR-based method for identification of lactobacilli at the genus level. FEMS Microbiol Lett 2002; 214: 271- 275.

15. Salminen $S$, Wright AV, Ouwehand AC. Lactic Acid Bacteria Microbiological and functional aspects. In: Marcel Dekker, Inc., editores. Lactic Acid Bacteria. Nueva York: Classification and Physiology; 2004.

16. Instituto Colombiano de Normas Técnicas y Certificación (ICONTEC). Norma Técnica Colombiana. NTC 4516, Microbiología de alimentos y productos de alimentación animal. Método horizontal para la detección y enumeración de coliformes. Técnica de número más probable. Primera actualización. ICONTEC 1998.
17. Instituto Colombiano de Normas Técnicas y Certificación (ICONTEC). Norma Técnica Colombiana. NTC 5230, Microbiología de alimentos y alimento para animales. Método horizontal de técnicas de muestreo de superficies usando cajas de contacto y método de escobillón. ICONTEC 2004.

18. O'Toole G, Kaplan HB, Kolter R. Biofilm formation as microbial development 2000. Annu Rev Microbiol 2000; 54:49-79.

19. Vasilopoulos C, Ravyts F, Maere De H, Mey De $E$, Paelinck $H$, Vuyst De L, Leroy $F$. Evaluation of the spoilage lactic acid bacteria in modified atmosphere-packaged artisan-type cooked ham using culturedependent and culture-independent approaches. J Appl Microbiol 2007; 1-13.

20. Schirmer BC, Heir E, Langsrud S. Characterization of the bacterial spoilage flora in marinated pork products. J Appl Microbiol 2009; 106:2106-2116.

21. Vasilopoulos C, Maere HD, Mey ED, Paelinck $H$, Vuyst LD, Leroy F. Technology-induced selection towards the spoilage microbiota of artisan-type cooked ham packed under modified atmosphere. Food Microbiology 2010; 27(1): 77-84.

22. Nathanon T. Biofilms and the food industry. Songklanakarin J Sci Technology 2003; 25(6): 807-815. 